\title{
SISTEMA INTEGRAL DE ASOCIATIVIDAD EMPRESARIAL CITRÍCOLA: PROPUESTA CAUSAL DE COMPETITIVIDAD
}

\author{
GERARDO DELGADO RIVAS \\ Facultad de Comercio y Administración Victoria \\ Universidad Autónoma de Tamaulipas, México \\ jdelgador@uat.edu.mx \\ MARITZA ÁLVAREZ HERRERA \\ Facultad de Comercio y Administración Victoria \\ Universidad Autónoma de Tamaulipas, México \\ ahmaritza@uat.edu.mx \\ NORMA PEDRAZA MELO \\ Facultad de Comercio y Administración Victoria \\ Universidad Autónoma de Tamaulipas, México \\ napedraza@uat.edu.mx
}

\section{RESUMEN}

En México, la citricultura representa la actividad frutícola más importante, los estados de Veracruz, San Luis Potosí y Tamaulipas son los principales productores de este tipo de cultivo. Asimismo, en términos de comercio internacional, los cítricos constituyen el cultivo de mayor valor. El estudio de perspectivas teóricas, a partir de la naturaleza de la presente investigación, requiere el análisis de la dinámica desarrollada entre las actividades, los recursos y las capacidades, así como la identificación de diversos elementos que explican la obtención de un posicionamiento competitivo.

PALABRAS CLAVE: CADENA DE VALOR, RECURSOS, CAPACIDADES, CLUSTER.

\section{ABSTRACT}

Citrus production represents the most important fruit farming activity in Mexico. Particularly, in states such as Veracruz, San Luis Potosí and Tamaulipas, it accounts for the majority of their production. Furthermore, in terms of international commerce, citrics is the harvest with the greatest economic value. The theoretical perspectives studied in the present re- search require the analysis of the dynamic development among activities, resources and capabilities, along with the identification of different elements that may explain its competitive positioning.

KEYWORDS: VALUE CHAIN, RESOURCES, CAPABILITIES, CLUSTER.

\section{INTRODUCCIÓN}

En la actualidad, las empresas se desenvuelven en un entorno cada vez más dinámico y complejo, lo cual se deriva de las exigencias propias de la globalización económica (Saavedra, 2010). De esta manera, se originan nuevas oportunidades de negocios, así como una alta presión competitiva que se caracteriza por la reducción del ciclo de vida del producto, altos costos de investigación y desarrollo, rápido cambio tecnológico e incertidumbre estratégica asociada a la globalización, entre otros (Taboada, 2004; Montegut, 2006). 
En este sentido, el hecho de alcanzar y sostener un posicionamiento competitivo en los mercados mediante el diseño de procesos y técnicas de gestión más eficientes, se traduce en una expectativa crucial para el éxito y supervivencia de las empresas (Aragón y Rubio, 2005).

La presión ejercida ha propiciado nuevas formas de organización en los eslabones de la cadena productiva, así como patrones de competencia que descansan cada vez más en las ventajas asociadas a la flexibilidad de la producción y de organización, lo que se verá reflejado tanto en el precio como en la calidad final del producto (Saavedra, 2010).

En consecuencia, se han suscitado procesos de desintegración vertical, además de distintas modalidades de cooperación entre empresas para enfrentar la competencia, una de las estrategias se refiere a la formación de clusters o conglomerados, cuyo eje central se sustenta en la competencia mediante la articulación de potencialidades existentes en los ámbitos locales y regionales para aprovechar el acceso a insumos, información y tecnología (Porter, 1999; Velázquez y Maldonado, 2010).

El análisis se centra en la identificación de los factores explicativos, tanto internos como externos, que les permitan a las empresas citrícolas de la región centro ${ }^{1}$ del estado de Tamaulipas obtener un mejor posicionamiento, lo anterior a partir de la identificación y análisis del conjunto de actividades (básicas y complementarias), recursos y capacidades, que representan el resultado de la trayectoria de cada organización y que difícilmente pueden ser imitados por la competencia.

1. En la investigación la región centro comprende los municipios de Victoria, Güémez, Padilla, Hidalgo, Villagrán, Mainero, Jiménez, Soto la Marina y Casas.
En este contexto, la citricultura en México caracteriza la actividad frutícola más importante, teniendo a los estados de Veracruz, San Luis Potosí y Tamaulipas como los principales productores de este tipo de cultivo. En el contexto socioeconómico, su importancia reside en la aportación de divisas y generación de empleos en cada una de las fases de la cadena productiva.

\section{Participación de México en el entorno internacional}

En el escenario internacional, México se considera como uno de los principales países productores de frutas cítricas frescas, registrándose en el periodo 2009 - 2010 una producción de 6350 toneladas en este tipo de cultivo, representando el 7,69\% con respecto al volumen producido mundialmente, lo cual le permitió ubicarse en el cuarto lugar, sólo por debajo de países como China, Brasil y Estados Unidos. Cabe destacar que del volumen producido en el país sólo 19,29\%, es decir 1,225 t, se destinó a algún proceso de industrialización, principalmente jugo de naranja, sin embargo también se empleó en la agroindustria para los sectores farmacéutico y de cosméticos (Díaz, 2010; Federación Argentina del Citrus, 2011).

En lo referente a las exportaciones, la participación de México en el año 2009 en relación con su nivel de productividad no se puede considerar del todo optimista, al ubicarse en el $8 \circ$ lugar a nivel mundial con 4,08\% de participación (Figura 1). 


\section{FIGURA 1 \\ EXPORTACIONES DE CÍTRICOS A NIVEL MUNDIAL (2009)}

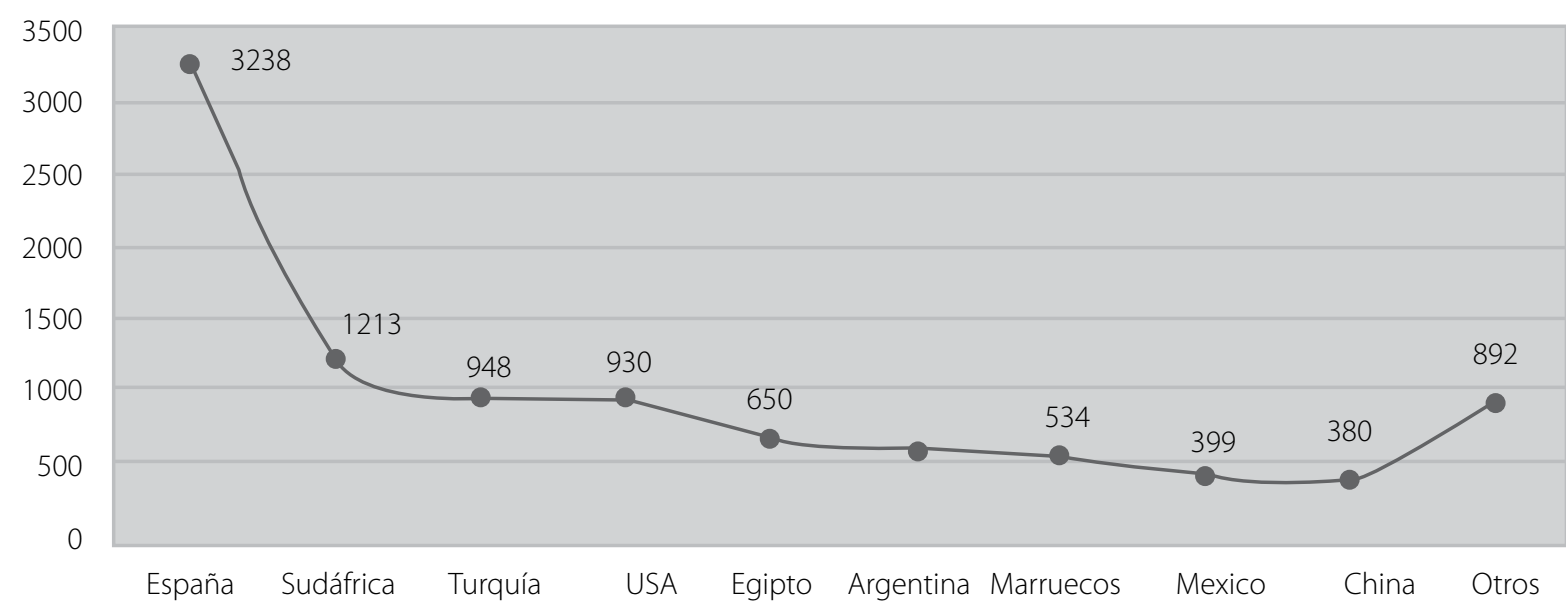

Fuente: Elaboración a partir de Secretaría de Agricultura, Ganadería, Desarrollo Rural, Pesca y Alimentación (SAGARPA, 2009).

\section{Tamaulipas en el entorno nacional citrícola}

En Tamaulipas, la actividad agropecuaria y forestal representa uno de los principales sectores económicos, de acuerdo con cifras del Instituto Nacional de Estadística y Geografía (2007), tal entidad federativa posee una superficie total de 5729 461,10 ha, de las cuales 56\% se encuentran destinadas a actividades primarias, ubicándose en esta dimensión de análisis en el quinto lugar con respecto a los demás estados del país. Además, las dos terceras partes de la superficie sembrada se mantienen con los periodos de lluvia del invierno y el resto mediante algún tipo de riego tecnificado.

En ese mismo año, el estado registró una significativa participación en el escenario citrícola en cuanto a la producción de este tipo de cultivo, se posiciona en el $2^{\circ}$ lugar a nivel nacional con una aportación de 12,40\% del volumen total.
En consecuencia, el sector primario, de acuerdo con cifras de INEGI (2009), representó 4,6\% del producto interno bruto (PIB) estatal. En este sentido, entre los productos primarios más importantes se encuentran el sorgo en grano, maíz, pasto, soya, cebolla, caña de azúcar, naranja y limón italiano (Gobierno del estado de Tamaulipas, 2011).

\section{Impacto de la región centro de Tamauli- pas en el sector citrícola estatal}

Al analizar la literatura, se evidencia que los principales municipios productores de cítricos se ubican en la región centro ${ }^{2}$ de la entidad, en conjunto concentran alrededor de $70 \%$ del volumen producido a nivel estatal (Figura 2).

2. En la presente investigación se considera como zona centro de Tamaulipas los municipios de Victoria, Güémez, Padilla, Hidalgo, Villagrán, Mainero, Jiménez, Soto la Marina y Casas. 
FIGURA 2

\section{PRINCIPALES MUNICIPIOS PRODUCTORES DE CÍTRICOS (2009)}

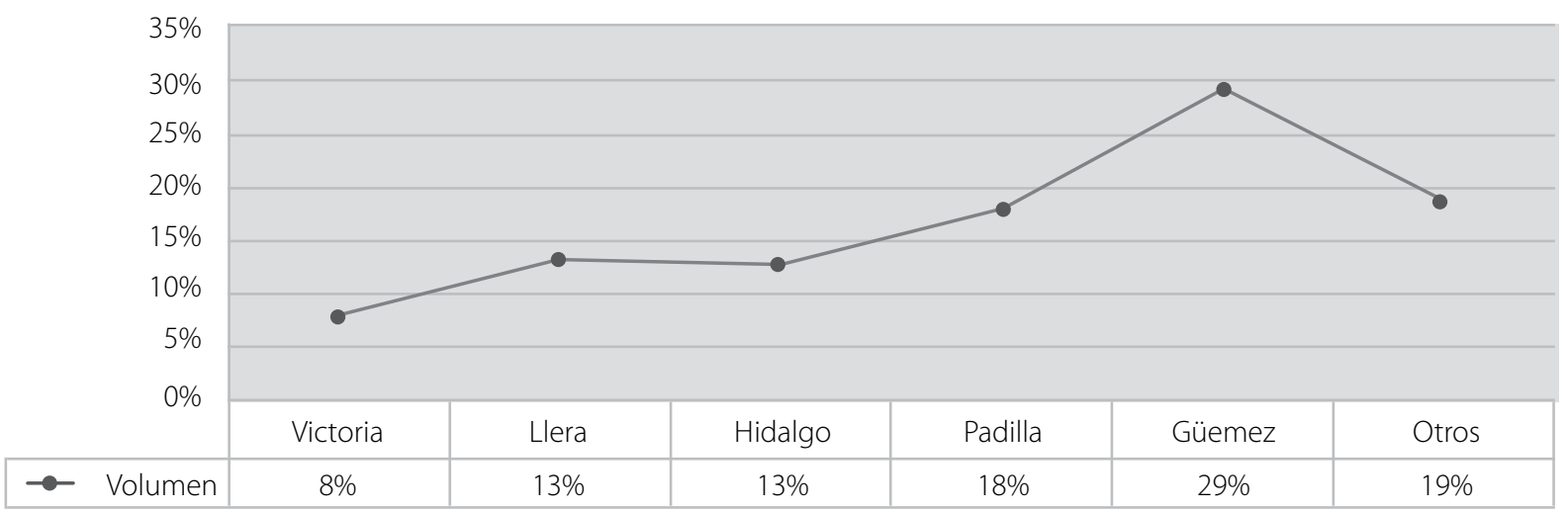

Fuente: Elaboración a partir de SAGARPA (2009).

FIGURA 3

\section{HUERTAS CERTIFICADAS PARA EXPORTAR A ESTADOS UNIDOS (2010)}

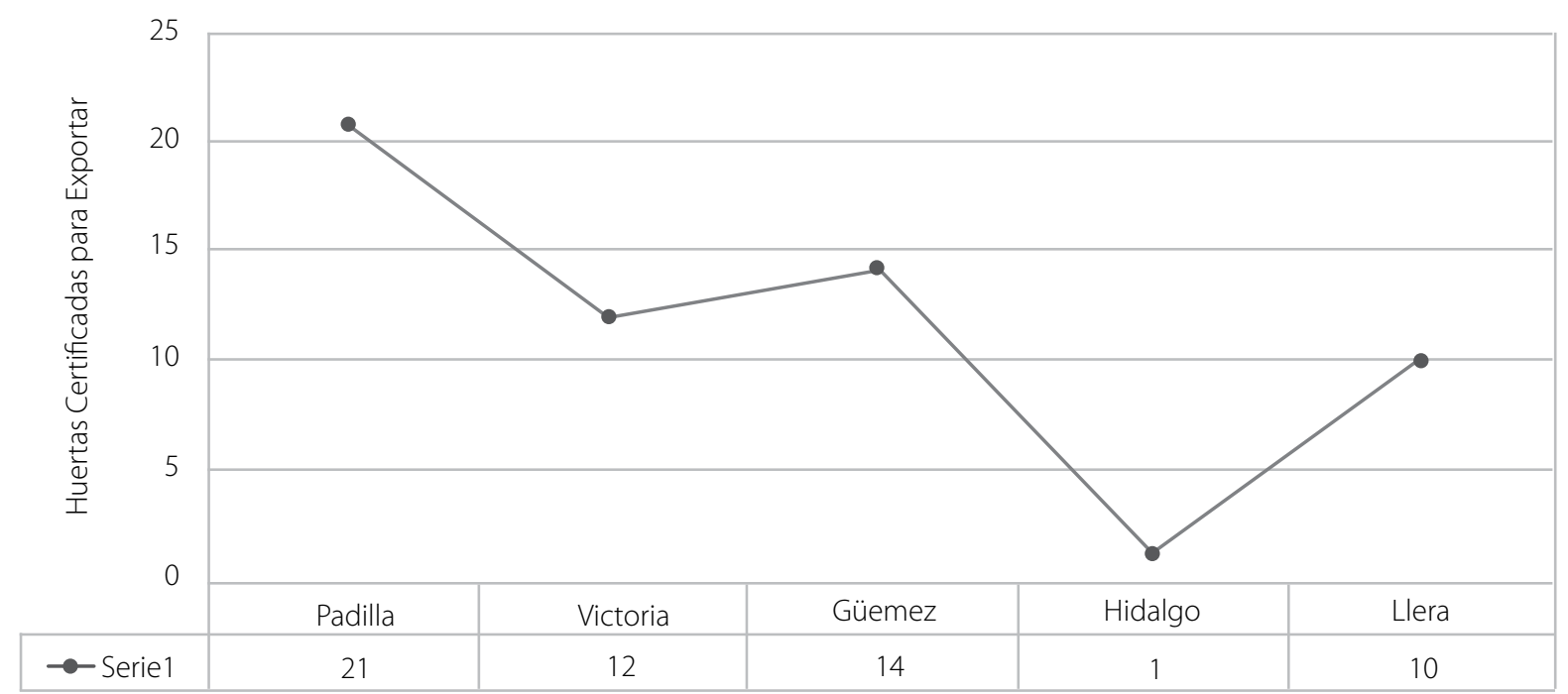

Fuente: Elaboración a partir de SAGARPA (2011).

Otro factor de análisis, de manera complementaria, lo representan las huertas certificadas para exportar a los Estados Unidos, registrándose que en el año 2010, de acuerdo con la SAGARPA, existían en la entidad un total de 58 productores, de los cuales $82,14 \%$ se localizaban en la zona centro del estado de Tamaulipas (Figura 3).
Por otra parte, la fase de industrialización de cítricos, en la que se consideran actividades de procesamiento, empacamiento y acopio de la fruta, se identifican 23 empresas en el estado, de las cuales $85,65 \%$ se localizan en la zona centro de la entidad (SAGARPA, 2011). 
EMPRESAS INDUSTRIALIZADORAS, EMPACADORAS Y CENTRO DE ACOPIO DE FRUTA CÍTRICA EN TAMAULIPAS (2011)

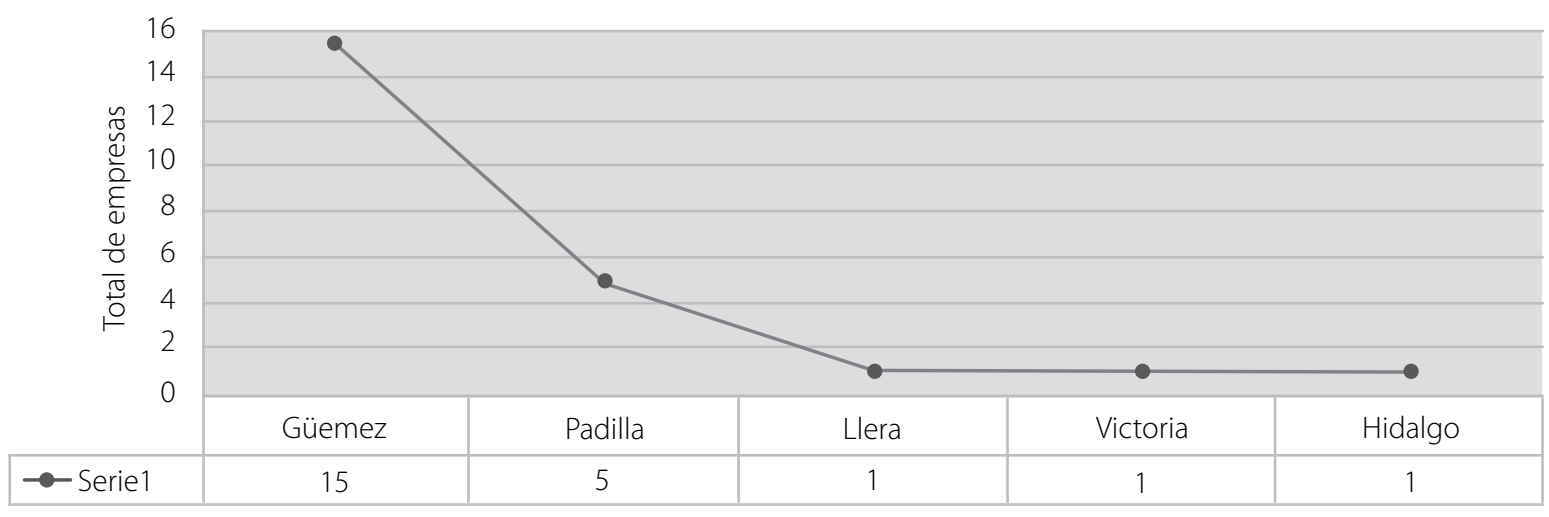

Fuente: Elaboración a partir de SAGARPA (2011).

La zona centro de Tamaulipas representa la región que concentra el mayor volumen de producción citrícola en la entidad. En este contexto, se destaca la relevancia de esbozar estrategias que contribuyan a lograr un mejor posicionamiento competitivo del sector, por lo que se plantea como principal propósito de esta investigación el diseño de un planteamiento estratégico sobre asociacionismo empresarial a partir de la identificación de los factores que contribuyen al éxito organizacional, el cual pueda aportar alternativas para la producción, industrialización y comercialización.

\section{Problemática del sector citrícola en Tamaulipas}

En los últimos años, la actividad citrícola en Tamaulipas presenta algunas problemáticas, las cuales para favorecer su análisis se categorizan atendiendo a las principales fases de la cadena productiva, tal como se muestra en la Figura 5.

FIGURA 5

\section{PROBLEMÁTICA DEL SECTOR CITRÍCOLA EN TAMAULIPAS}

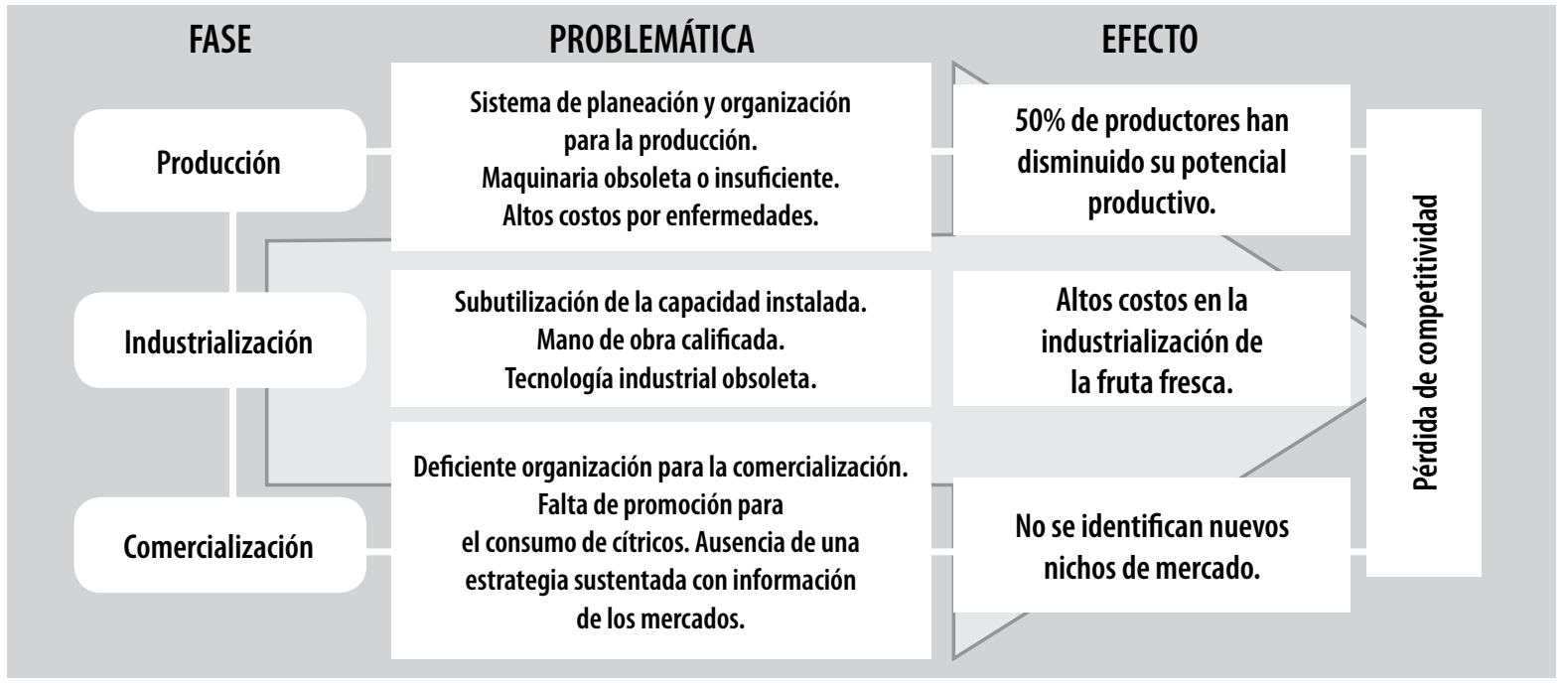

Fuente: Elaboración a partir de SAGARPA (2004 y 2009). 
En este contexto, se debe puntualizar la necesidad de abordar estrategias que modernicen el esquema organizativo tradicional de la citricultura, lo anterior a partir de la potencialización de los recursos y capacidades implicados en los distintos procesos orientados a competir en mercados globales.

\section{La cadena de valor, los recursos y las capacidades: factores determinantes del posicionamiento competitivo}

El estudio de diversas perspectivas teóricas relacionadas con la naturaleza de la investigación, requirió la identificación y análisis de planteamientos que abordaran el tema de competitividad. Por una parte, el conjunto de actividades y procesos que interactúan e integran la cadena de valor de empresas citrícolas; por otra, la determinación de los recursos y capacidades que poseen las empresas.

Al respecto, en la figura 6 se presenta la estructura epistemológica de la presente investigación, en la que se permite identificar los elementos teóricos concluyentes hacia la obtención de un posicionamiento competitivo, lo anterior como referente para esbozar un esquema de integración empresarial.

\section{Actividades y procesos como elementos determinantes de la cadena de valor}

Los planteamientos que abordan el concepto de cadena de valor han evolucionado (Díaz y Hartwich, 2005), existen diversos enfoques que permiten disgregar las actividades individuales de cada agente económico, actividades que participan en un sistema de rutinas o procesos interdependientes (Porter, 1987). En este sentido, adquiere un mayor significado identificar aquellas que constituyen un factor de competitividad sobre sus competidores.

En este contexto, el logro de un posicionamiento competitivo que impacta en la actividad citrícola se basa en la calidad de los productos, así como en la capacidad de adaptarse y satisfacer los requerimientos del cliente, motivo por el cual ha surgido una amplia variedad en las presentaciones mediante procesos de industrialización (Server y Mateos, 2003). De esta manera, algunas alternativas para el uso, o en su caso el consumo, de productos citrícolas son las siguientes: aceites esenciales o cosmetológicos, carotinoides,

Figura 6

MARCO TEÓRICO DE LA INVESTIGACIÓN

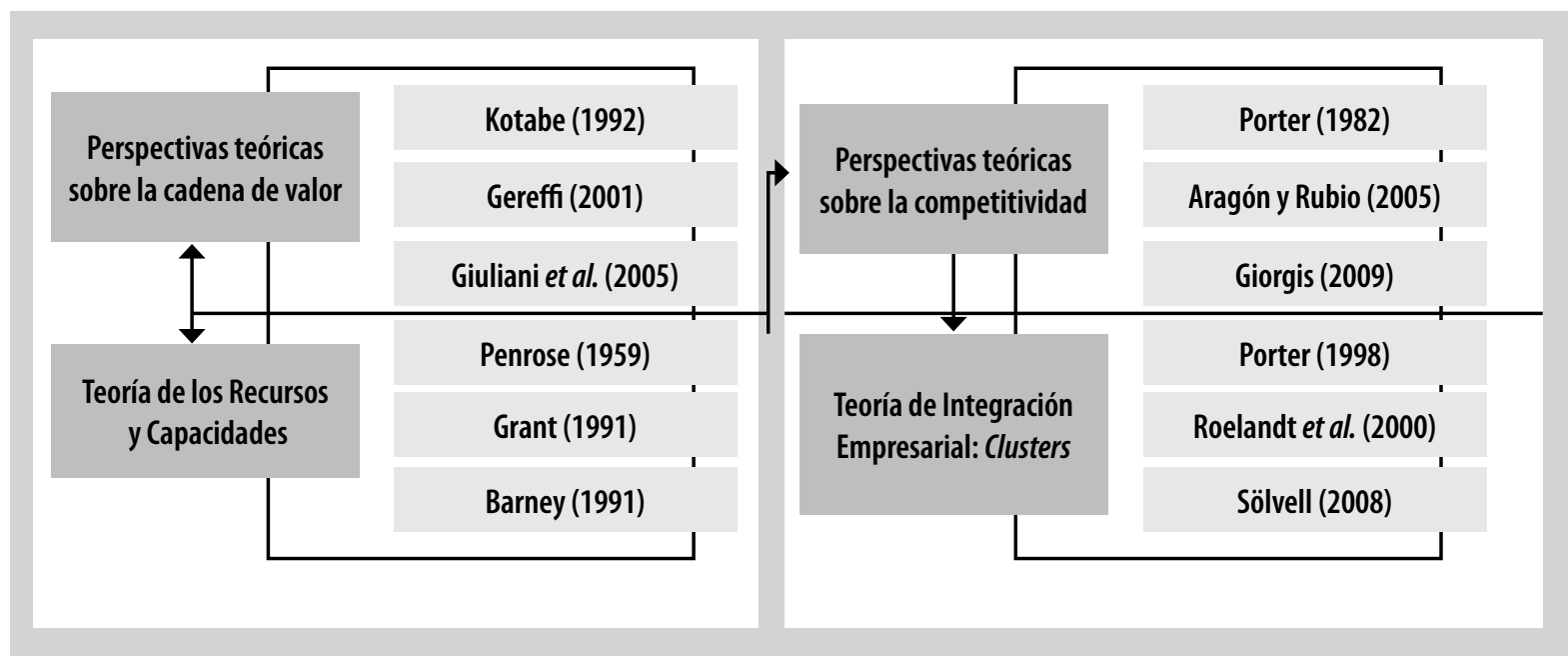

Fuente: Elaboración propia. 
aceite comestible, alimento para ganado, entre otras (SAGARPA, 2009).

Bair y Gereffi (2001) consideran que las empresas participan en entornos económicos cada vez más globalizados, dada la apertura comercial, lo cual origina brechas de oportunidad más amplias para cada organización. En este sentido, se desarrolla el planteamiento de analizar de forma global las cadenas de valor, es decir, de considerar que la producción, la transformación y el consumo puedan realizarse en distintos lugares.

Bajo esta perspectiva de análisis, se incluye a los agentes que aportan insumos y aquellos que participan en los canales de distribución, es decir, los enlaces no sólo se originan al interior de la misma empresa entre las distintas actividades (primarias y de apoyo), sino que se podrán crear interdependencias con proveedores e instituciones de soporte. En consecuencia, se estará en posibilidad de mejorar su posicionamiento competitivo en el momento de que se optimicen los enlaces con su entorno, lo cual propicia la integración de la cadena productiva del sector que abarca una serie de componentes para crear el producto final que se ha de comercializar (Buitelaar, 2001; Alvarez, 2011).
En vista de lo anterior, se consideran diversos agentes económicos que participan en el proceso realizado en las cadenas agroalimentarias, particularmente en la referente al sector citrícola en Tamaulipas, el cual inicia con la proveeduría de insumos y servicios a partir de la fase de producción, continúa en los canales de distribución utilizados para llevar el producto final al consumidor (Chavarría, Sepúlveda y Rojas, 2002; SAGARPA, 2004). Al respecto, en la figura 7 , se presentan los vínculos existentes entre las empresas que participan en este tipo de actividad primaria.

\section{Los recursos y capacidades como factores explicativos del éxito competitivo en el sector citrícola}

Diversos planteamientos epistemológicos consideran en una empresa, o conjunto de ellas, la existencia de un portafolio de capacidades a todos los niveles de la organización, las cuales se podrán optimizar a partir de una selección de recursos. En consecuencia, la eficiente relación que se origine entre ambos elementos (recursos y capacidades), permitirá crear ventajas competitivas para el logro de beneficios como obtener

FIGURA 7

\section{AGENTES ECONÓMICOS EN EL SECTOR CITRÍCOLA DE TAMAULIPAS}

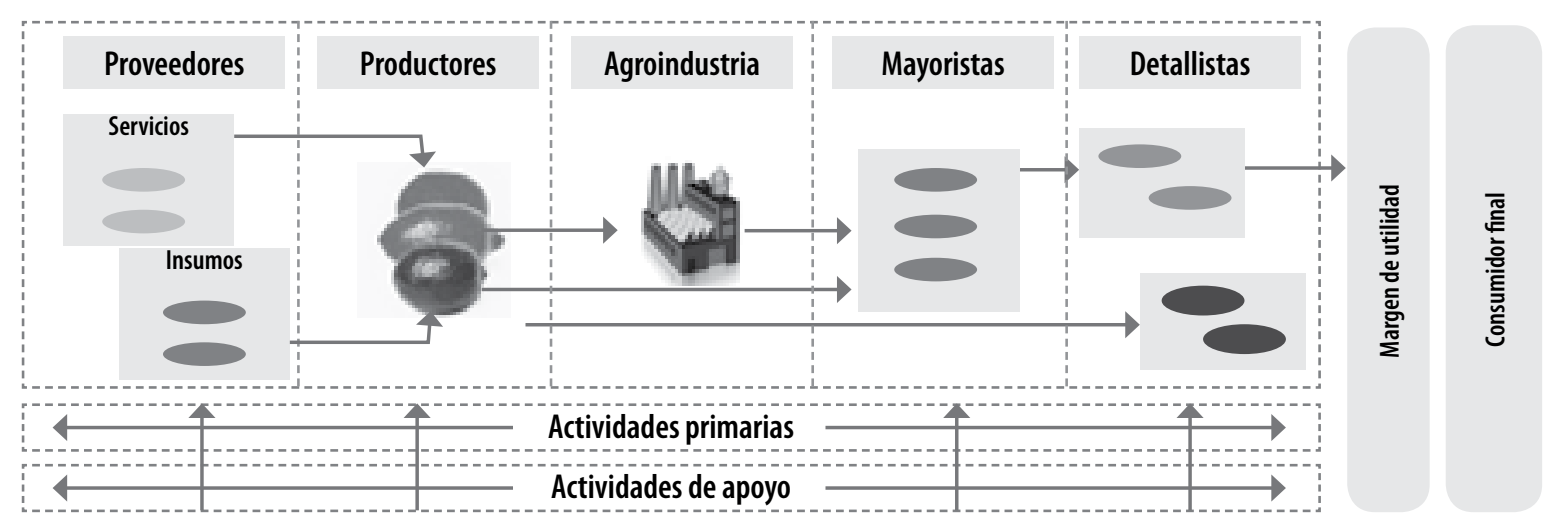

Fuente: Elaboración a partir de Porter (1987), SAGARPA (2004) y Álvarez (2011). 
rendimientos superiores a los estimados, activos extraordinarios, el logro de una mayor longevidad operacional y un mejor posicionamiento en el mercado con respecto a determinado sector, industria o competencia (De la Cruz, 2008).

En este sentido, se produce el argumento de la existencia de ciertos factores internos que constituyen el principal sustento de la excelencia empresarial de cara a la obtención de un mejor posicionamiento en el mercado (Rubio y Aragón, 2008). Así, el reto consiste en explicar las causas de mejores niveles de eficiencia en las organizaciones, en pequeña o gran escala, aun cuando participan en la misma actividad económica. Como se anotó, mediante la eficiente vinculación entre los recursos y las capacidades es posible fortalecer la competitividad, por tanto ambos conceptos representan un motivo de análisis que explique la evolución de los resultados empresariales.

Una empresa se encuentra integrada por una colección de recursos y acumulación de conocimientos capaces de proporcionar ciertos servicios diferenciados, dando lugar a la proliferación de beneficios a largo plazo a partir del aprovechamiento de las oportunidades presentadas (Penrose, 1959). En consecuencia, la búsqueda de un mejor posicionamiento competitivo proviene de la supervivencia en el sector y los negocios que la integran, lo cual determinará en gran medida su permanencia en el mercado (De la Cruz, 2007).

En términos prácticos, las capacidades no significan solamente una consecuencia del conjunto de recursos individuales que la empresa posee o controla, se requiere de una actuación deliberada que se encuentre encaminada a la integración y coordinación de tales recursos mediante el desarrollo eficiente de rutinas organizativas para conseguir ventajas sobre sus competidores (Server y Mateos, 2003; Urgal, 2005; Rubio y Aragón, 2008).

\section{Otros planteamientos teóricos sobre la competitividad}

En la actualidad, las organizaciones se están enfrentando a cambios importantes en el entorno, como la competencia más aguda, la sofisticación de la tecnología, los cambios económicos y la globalización de la economía, entre otros (Estrada, García y Sánchez, 2009). Por lo anterior, la competitividad se podrá entender como un concepto dinámico, complementado por la innovación y búsqueda de estrategias organizaciones diferenciadas, las cuales se interrelacionan e influyen directamente con el uso óptimo de las capacidades para transformar insumos.

En este contexto, no basta la percepción tradicional de que la competitividad está determinada sólo por la abundancia o escasez de los recursos con los que cuenta la empresa, sino que se requiere del análisis integral de factores para un adecuado funcionamiento, como el nivel e innovación tecnológica, la organización, la protección del medio ambiente y la política económica (Vera y Ganga, 2007; Romo y Abdel, 2005; Villafán, Guitrón, Pedraza y Bonales, 2007).

Por otra parte, al analizar diversos planteamientos metodológicos, se consideran factores internos que impactan en la competitividad empresarial los siguientes: la planeación estratégica, la producción y operaciones, las capacidades directivas de comercialización y de marketing, el aseguramiento de la calidad, la gestión y dirección de los recursos humanos, la cultura organizacional así como los sistemas de información, entre otros (Jiménez, 2006; Rubio y Aragón, 2008; Rodríguez, Bañuelos, Rubio y Chávez, 2010; Saavedra, 2010).

A manera de síntesis, en la tabla 1, se identifican los principales factores internos que han sido propuestos como determinantes en el posicionamiento competitivo de las organizaciones. 
TABLA 1

FACTORES INTERNOS DE COMPETITIVIDAD EMPRESARIAL

\begin{tabular}{|l|c|c|c|c|c|}
\hline \multicolumn{1}{|c|}{ Factores } & $\begin{array}{c}\text { Jiménez } \\
\text { (2006) }\end{array}$ & $\begin{array}{c}\text { Rubio y Aragón } \\
\text { (2008) }\end{array}$ & $\begin{array}{c}\text { Estrada et al. } \\
\text { (2009) }\end{array}$ & $\begin{array}{c}\text { Rodríguez et al. } \\
\text { (2010) }\end{array}$ & $\begin{array}{c}\text { Saavedra } \\
\text { (2010) }\end{array}$ \\
\hline Recursos humanos & & $X$ & $X$ & & $X$ \\
\hline Recursos tecnológicos & $X$ & $X$ & $X$ & $X$ & $X$ \\
\hline Innovación & $X$ & $X$ & $X$ & & $X$ \\
\hline Gestión comercial & & $X$ & $X$ & $X$ & $X$ \\
\hline Aseguramiento de la calidad & & $X$ & $X$ & $X$ & $X$ \\
\hline Planeación estratégica & $X$ & $X$ & & & $X$ \\
\hline Capacidades directivas & & $X$ & & & $X$ \\
\hline Cultura de la organización & $X$ & & & $X$ \\
\hline Producción y operaciones & & & & & $X$ \\
\hline Gestión contable & & & & & \\
\hline Aspectos bancarios & & & & & $X$ \\
\hline Gestión ambiental & & & & $X$ \\
\hline Internacionalización & & & & $X$ \\
\hline
\end{tabular}

Fuente: Elaboración propia con base en los autores precitados.

Como se aprecia, la literatura científica presenta evidencia de estudios realizados sobre competitividad empresarial, en donde se identifica que el referente común lo constituyen las aportaciones en relación con la teoría de recursos y capacidades así como a la cadena de valor, ambas como factores explicativos del éxito obtenido por las organizaciones, el cual no es producto de una casualidad o espontaneidad, sino que permitirá consolidarlas en los mercados locales, trascender fronteras y obtener una posición destacada en el sector en que se participe (Demuner, Aguilera y Hernández, 2010).

En este contexto, existe la necesidad de crear factores y competencias en economías enmarcadas por el escaso desarrollo, no siendo una tarea exclusiva del sector público mediante las políticas gubernamentales diseñadas a un nivel microeconómico, sino que se debe propiciar la participación de los sectores productivos para generar una competitividad sostenida (PadillaBernal, Reyes-Rivas y Pérez-Veyna, 2010).

\section{La integración empresarial como un modelo de negocio: los clusters}

Ante un panorama significativamente volátil en el comportamiento de los mercados, las tendencias a alcanzar mayor competitividad requieren que las empresas adopten esquemas de integración empresarial, de manera que compitan de una mejor manera a través de la cooperación. Es decir, el grado de incertidumbre que provoca el entorno en el que se encuentran inmersas las organizaciones permite explicar su comportamiento, que estructura las relaciones de intercambio por medio de vínculos con otras entidades (Sanfiel, Oreja, García y Álvarez, 2005).

Por lo anterior, se considera cluster o conglomerado a la existencia de concentraciones empresariales interrelacionadas en un determinado espacio geográfico, que orientan sus actividades a un sector de la producción en el que se agrupan una 
diversidad de organizaciones (Porter, 1982). Además, se complementa con la integración de redes de proveedores, organismos gubernamentales, así como instituciones o centros de investigación que proveen entrenamiento, educación, información, investigación y soporte técnico (Sölvell, 2008).

Es decir, un cluster representa un mecanismo en el que participan una diversidad de empresas e instituciones públicas, con la intención de fortalecer un sector determinado donde se articulan las potencialidades existentes en los ámbitos locales o regionales (Velázquez y Maldonado, 2010). En este contexto, la aglomeración de empresas en una proximidad geográfica podrá generar beneficios para sus integrantes, entre los cuales se citan la cercanía con proveedores de insumos, maquinaria, servicios auxiliares y de soporte en forma más accesible y a bajo costo con la oportunidad de abastecerse localmente, la abundancia de mano de obra calificada reduciendo costos en capacitación, el acceso a la información especializada y a las tecnologías y la facilidad en la comercialización y venta por la afluencia de clientes potenciales (Porter, 1999; Meyer-Stamer y Harmes-Liedtke, 2005).

En este sentido, uno de los mecanismos que ha impactado favorablemente en el posicionamiento competitivo de las empresas y de ciertas regiones lo constituye el cluster (Chami, 2001); en el ámbito nacional se pueden citar el cluster del aguacate en Michoacán (Villafán, et al., 2007), el cluster mueblero en Aguascalientes (Díaz y Feria, 2008), el cluster del software en Yucatán (Caro y Leyva, 2007), el cluster del jitomate en Baja California (Velázquez y Maldonado, 2010), el cluster del calzado en Guanajuato (Unger, 2003), entre otros.

En tanto, como referentes internacionales, se identifican en los Estados Unidos el cluster de vinos (Porter, 1999), así como el cluster de las tecnologías de la información (Sölvell, 2008), en Noruega el cluster marítimo (Rueda, 1997), en Chile el cluster de harina de pescado (Montero, 2004), en Costa Rica el cluster eco-turístico (Acuña, ViIlalobos y Ruíz, 2000), en Venezuela el cluster de la sábila (Piña, 2004), en Argentina el cluster oleaginoso (Ramos, 1998), entre otros casos de éxito.

\section{METODOLOGÍA}

En esta investigación de tipo cualitativa, las distintas fases que la integran se sucedieron en forma lineal, es decir, una vez que se identificó el tema por tratar, se llegó al primer acercamiento, el cual se caracteriza por ser de tipo documental, representado por la recolección de datos a partir de un marco referencial constituido principalmente por el análisis a los planteamientos propuestos por diversos autores (Eisenhardt, 1989; Yin, 1991; Silverman, 1993; Rodríguez et al., 1999; Bonache, 1999).

La estrategia de investigación se apoyó en un estudio multicaso de tipo instrumental, para lo cual se revisó el tema central a lo largo de diferentes tipologías de unidades de análisis que fueron seleccionadas siguiendo el criterio de muestreo por conveniencia no probabilístico. Para la determinación del número de casos necesarios en este tipo de investigación, se propuso que no fuera inferior a cuatro ni superior a diez (Eisenhardt, 1989).

En este sentido, la selección de casos se realizó a partir de las empresas con localización geográfica en la región centro del estado de Tamaulipas, las cuales han logrado transitar de la fase de producción a la de valor agregado en los cítricos, o bien, trascender a prácticas de comercialización de los mercados locales hacia los internacionales. En este sentido, se consideró conveniente identificar los factores de éxito que han impactado favorablemente en su posicionamiento competitivo.

A continuación, en la tabla 2, se identifican a manera de síntesis las características distintivas de las unidades de análisis. 
TABLA 2

\section{GENERALIDADES DE LAS UNIDADES DE ANÁLISIS}

\begin{tabular}{|c|c|c|c|c|c|}
\hline \multirow{2}{*}{ Empresa } & Ubicación & Año Inicio & Directa & Actividad & Indirecta ("brokers") \\
\hline "Valencia" & Victoria & 1974 & $\begin{array}{c}\text { Producción, valor agregado } \\
\text { y comercialización (mercado nacional) }\end{array}$ & Exportación \\
\hline "Eureka" & Güémez & 1978 & Producción y valor agregado & Comercialización \\
\hline "Alkantara" & Güémez & 2004 & Producción, valor agregado y exportación & Limón y naranja \\
\hline "Delta" & Victoria & 2002 & Industrialización & Limán \\
\hline
\end{tabular}

Fuente: Elaboración a partir de entrevistas con gerentes.

Una vez que se seleccionaron los casos de estudio, se emplearon los mecanismos para la recolección de la información de acuerdo con la naturaleza de la investigación. Por una parte, se consultaron fuentes secundarias, como revistas, boletines, sitios web e informes, los cuales permiten la identificación y análisis del entorno que rodea a la actividad citrícola.

Posteriormente, durante los meses de junio y julio de 2011, se realizaron las entrevistas semiestructuradas a dueños o gerentes, con una duración que osciló entre 40 a 120 minutos. Las conversaciones fueron grabadas previo consentimiento de cada entrevistado. En términos generales, las preguntas fueron breves, mientras que las respuestas amplias y espontáneas, lo cual resultó en una riqueza de la información obtenida.

En forma paralela, se efectuó la observación directa, que consistió en la interacción mediante la observación de artefactos físicos, tecnológicos y culturales, proceso en el que se tomaron notas detalladas.
Realizar una investigación representa un proceso que requiere llevar a cabo una fase destinada a la planeación de las diversas actividades que se van a ejecutar (Namakforoosh, 2006), lo anterior con el objetivo de utilizar eficientemente los recursos destinados a cumplir el propósito propuesto. En este sentido, en la figura 8, se muestra el esquema metodológico sobre la operacionalización de las fases que integran el proceso de investigación.

Para el procesamiento de datos, se utilizó el análisis de contenido por ser considerado una estrategia que permite analizar los procesos de comunicación en muy diversos contextos (Hernández et al., 2003). Por lo anterior, una vez que se obtuvo la información mediante la aplicación de las entrevistas, se elaboró un manual de codificación, en el que se presentan los datos de manera organizada de acuerdo con categorías, variables y códigos, lo anterior con la finalidad de diseñar las matrices de concentración y el posterior análisis de contenido de forma individual. 


\section{PROCESO DE LA INVESTIGACIÓN}

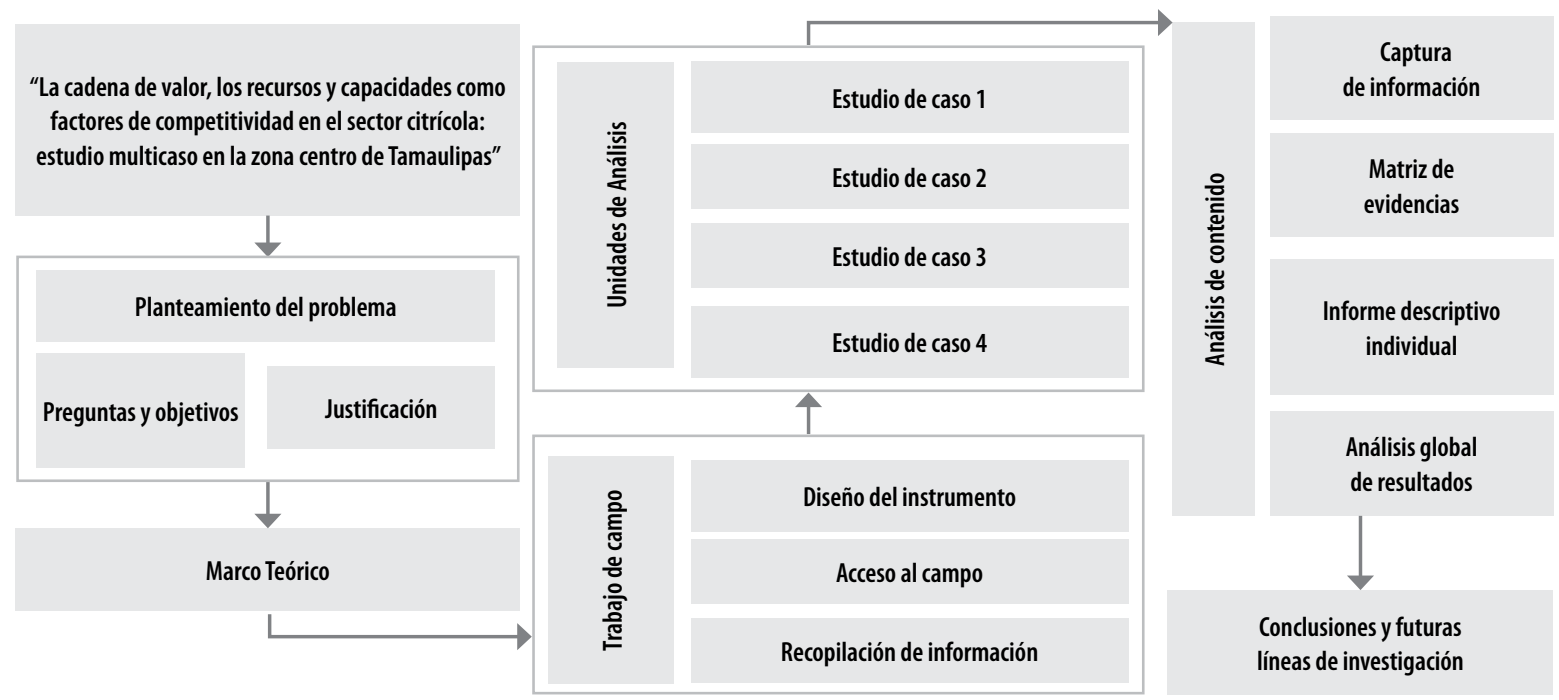

Fuente: Elaboración a partir de Rodríguez et al. (1999) y Alvarez (2011).

\section{RESULTADOS}

Para analizar las actividades desarrolladas en las empresas estudiadas, se han clasificado en: a) básicas, orientadas desde la creación física del producto hasta la asistencia posterior a su venta; $y, b)$ transversales o de apoyo, es decir, complementan las actividades básicas.

En la tabla 3, se presenta la matriz que concentra las actividades desarrolladas en las distintas fases realizadas al interior de las respectivas unidades de análisis.

TABLA 3

\section{MATRIZ DE CONCENTRACIÓN PARA IDENTIFICAR LAS ACTIVIDADES BÁSICAS Y TRANSVERSALES}

\begin{tabular}{|l|c|c|c|c|}
\hline \multicolumn{1}{|c|}{ Actividad } & Valencia & Eureka & Alkantara & Delta \\
\hline GESTIÓN ORGANIZACIONAL & & & \\
\hline Control Interno para la contratación de personal & $X$ & $X$ & $X$ \\
\hline Sistema de control de inventarios & $X$ & $X$ & 4 \\
\hline Compra de fruta fresca & & & $X$ \\
\hline Manual de procedimientos & $X$ & $X$ & $X$ \\
\hline
\end{tabular}


continuación tabla 3

\begin{tabular}{|c|c|c|c|c|c|}
\hline Sistematización de la producción & $X$ & $X$ & $X$ & & 3 \\
\hline Procedimientos de seguridad e higiene laboral & & $x$ & & & 1 \\
\hline Recepción de fruta para maquila (outsourcing) & $x$ & $X$ & & & 2 \\
\hline Traslado y almacenamiento de la fruta & $x$ & $x$ & $x$ & & 3 \\
\hline Diseño y monitoreo de indicadores & & & $x$ & $x$ & 2 \\
\hline \multicolumn{6}{|l|}{ PRODUCCIÓN } \\
\hline Producción limón italiano (labores culturales) & $x$ & $x$ & $X$ & & 3 \\
\hline Producción naranja (labores culturales) & & $X$ & $X$ & & 2 \\
\hline Producción toronja (labores culturales) & & & $X$ & & 1 \\
\hline Valor agregado & $X$ & $x$ & $X$ & & 3 \\
\hline Valor agregado ("outsourcing") & $x$ & $x$ & & & 2 \\
\hline Industrialización (jugo, aceite, pulpa, cascarilla) & & & & $x$ & 1 \\
\hline \multicolumn{6}{|l|}{ LOGÍSTICA DE SALIDA } \\
\hline Comercialización mercado interno & $x$ & & $x$ & & 2 \\
\hline Comercialización mercado interno "broker" & & $x$ & & & 1 \\
\hline Exportación"broker" & $x$ & $x$ & & $x$ & 3 \\
\hline Exportación directa & & & $X$ & & 1 \\
\hline \multicolumn{6}{|l|}{ MARKETING } \\
\hline Ferias internacionales (expositor) & $x$ & & $x$ & & 2 \\
\hline Ferias internacionales (asistente) & & $x$ & & & 1 \\
\hline Página electrónica & & $x$ & $x$ & & 2 \\
\hline \multicolumn{6}{|l|}{ SERVICIO POST-VENTA } \\
\hline Identificación del grado de satisfacción & $x$ & & & & 1 \\
\hline Reuniones para identificar grado de satisfacción & & & $X$ & & 1 \\
\hline
\end{tabular}


RNA Revista Nacional de Administración

continuación tabla 3

\begin{tabular}{|c|c|c|c|c|c|}
\hline Vía telefónica & & & $X$ & & 1 \\
\hline \multicolumn{6}{|l|}{ ABASTECIMIENTO } \\
\hline Compra de insumos: proveeduría local & & & $x$ & $x$ & 2 \\
\hline Compra de insumos: proveeduría nacional & $x$ & & & $x$ & 2 \\
\hline Compra de insumos: proveeduría internacional & & $x$ & & & 1 \\
\hline Servicios especializados: proveeduría internacional & $x$ & $x$ & $x$ & $x$ & 4 \\
\hline \multicolumn{6}{|l|}{ INFRAESTRUCTURA ORGANIZACIONAL } \\
\hline Área administrativa & $x$ & $x$ & $x$ & $x$ & 4 \\
\hline Área de producción & $x$ & $x$ & $x$ & $x$ & 4 \\
\hline Área de negocios internacionales (logística) & $x$ & $x$ & $x$ & & 3 \\
\hline Área de control de calidad & $x$ & & & $x$ & 2 \\
\hline Bitácoras de actividades & $x$ & $x$ & $x$ & & 3 \\
\hline Planeación estratégica. & $x$ & $x$ & $x$ & $x$ & 4 \\
\hline \multicolumn{6}{|l|}{ CAPITAL HUMANO } \\
\hline Exámenes psicométricos & $x$ & & & & 1 \\
\hline Programas de capacitación & $x$ & $x$ & $x$ & $x$ & 4 \\
\hline Rotación de personal & & & $x$ & & 1 \\
\hline Sistema de escalafón & & & & $x$ & 1 \\
\hline \multicolumn{6}{|l|}{ DESARROLLO TECNOLÓGICO } \\
\hline Implementación de sistema de trazabilidad & $X$ & $x$ & $x$ & & 3 \\
\hline Sistematización en el área contable & $X$ & $x$ & $x$ & $x$ & 4 \\
\hline Innovación industrialización & & & & $X$ & 1 \\
\hline Desarrollo de página web & & $x$ & $x$ & & 2 \\
\hline
\end{tabular}

Fuente: Elaboración a partir de las entrevistas realizadas.

1324 (1), Enero - Junio, 2013 
De igual forma, con base en la información obtenida, se identificaron los recursos y capacidades, que se poseen o en su caso se desarrollan al interior de cada empresa analizada (Tabla 4).

\section{MATRIZ DE CONCENTRACIÓN PARA IDENTIFICAR LOS RECURSOS Y CAPACIDADES}

\begin{tabular}{|c|c|c|c|c|c|}
\hline $\begin{array}{c}\text { Factor de análisis } \\
\text { Categoría } \\
\text { Variable }\end{array}$ & Valencia & Eureka & Alkantara & Delta & Total \\
\hline \multicolumn{6}{|l|}{ RECURSOS DE LA EMPRESA } \\
\hline \multicolumn{6}{|l|}{ Recursos tangibles } \\
\hline Superficie para la producción & $x$ & $X$ & $x$ & & 3 \\
\hline Tecnificación en las huertas & & $X$ & $X$ & & 2 \\
\hline Planta de empaque & $x$ & $x$ & $x$ & & 3 \\
\hline Cuartos de desverdizado & $x$ & $x$ & $x$ & & 3 \\
\hline Laboratorios especializados & & & & $x$ & 1 \\
\hline Planta procesadora de cítricos & & & & $x$ & 1 \\
\hline \multicolumn{6}{|l|}{ RECURSOS INTANGIBLES } \\
\hline Marca comercial & $x$ & $x$ & $x$ & & 3 \\
\hline Experiencia en el sector & $x$ & $x$ & $x$ & $x$ & 4 \\
\hline Adopción de sistemas tecnológicos & $x$ & $x$ & $X$ & $X$ & 4 \\
\hline Página electrónica & & $x$ & $x$ & & 2 \\
\hline \multicolumn{6}{|l|}{ RECURSOS FINANCIEROS } \\
\hline Estrategia de liquidez financiera & $x$ & & & & 1 \\
\hline Inversión en producción primaria & $x$ & & & & 1 \\
\hline Ingresos por "outsourcing" & $x$ & $x$ & & & 2 \\
\hline Inversión en capacitación continua & $X$ & $X$ & $x$ & $x$ & 3 \\
\hline Venta total de la producción & & & & $x$ & 1 \\
\hline Inversión en tecnología & & $x$ & $x$ & $x$ & 3 \\
\hline \multicolumn{6}{|l|}{ CAPACIDADES DE LA EMPRESA } \\
\hline Directivas & & & & & \\
\hline
\end{tabular}

continúa... 
RNA Revista Nacional de Administración

continuación tabla 4

\begin{tabular}{|c|c|c|c|c|c|}
\hline Incrementar la productividad & $X$ & $X$ & & & 2 \\
\hline Calidad de la producción & $x$ & $x$ & $x$ & $x$ & 4 \\
\hline Mayor rentabilidad por variedad & $x$ & & & & 1 \\
\hline Mayor rendimiento en el procesamiento & & & & $X$ & 1 \\
\hline Conocimiento del entorno citrícola & $X$ & $X$ & $X$ & $X$ & 4 \\
\hline Internacionalización de la empresa & $x$ & $x$ & $x$ & $x$ & 4 \\
\hline \multicolumn{6}{|l|}{ LABORALES } \\
\hline Habilidades en prácticas agronómicas & $X$ & $x$ & $X$ & & 3 \\
\hline Valor agregado artesanal & $x$ & & & & 1 \\
\hline Capacitación en valor agregado tecnificado & & $x$ & $x$ & & 2 \\
\hline Capacitación en industrialización & & & & $x$ & 1 \\
\hline Compromiso con la empresa & & & $x$ & & 1 \\
\hline \multicolumn{6}{|l|}{ COMERCIALES } \\
\hline Alianzas en valor agregado & $x$ & & & & 1 \\
\hline Relación precio-calidad & $x$ & $x$ & $x$ & & 3 \\
\hline Outsourcing en valor agregado & $x$ & $X$ & & & 2 \\
\hline Diversificación de la oferta & & & $x$ & & 1 \\
\hline Alianzas en comercialización & & & $x$ & & 1 \\
\hline Convenios para la comercialización & $x$ & $x$ & & $x$ & 3 \\
\hline \multicolumn{6}{|l|}{ TECNOLÓGICAS } \\
\hline Asimilación de las TIC & $x$ & $X$ & $x$ & $x$ & 4 \\
\hline I+D en sistemas para mayores rendimientos & & & & $x$ & 1 \\
\hline \multicolumn{6}{|l|}{ ASEGURAMIENTO DE LA CALIDAD } \\
\hline Certificaciones internacionales & $x$ & $x$ & $x$ & $x$ & 4 \\
\hline Programa de capacitación en calidad & $X$ & $X$ & $x$ & $X$ & 4 \\
\hline
\end{tabular}

Fuente: Elaboración a partir de las entrevistas realizadas.

1344 (1), Enero - Junio, 2013 


\section{Factores de competitividad en el sector citrícola del estado de Tamaulipas}

El éxito competitivo empresarial se encuentra determinado por un conjunto de factores externos e internos de competitividad (Martínez, Charterina y Araujo, 2010). A continuación se presentan los factores explicativos del éxito competitivo en las empresas analizadas.

\section{Factores internos de competitividad}

Según Rubio y Aragón (2008), los factores internos que contribuyen al éxito competitivo que han sido más estudiados son los recursos tecnológicos, la innovación, los recursos comerciales, la calidad del producto, las capacidades directivas y la cultura de la organización. En la tabla 5, se identifican los elementos que impactan en el posicionamiento de las respectivas unidades de análisis.

Al respecto, las empresas "Valencia", "Eureka" y "Alkantara" consideran, como factor interno clave para un mejor posicionamiento competitivo, la obtención de certificaciones con reconocimiento internacional sobre el cumplimiento de estándares de calidad en los productos que ofertan, lo cual les ha permitido incursionar con éxito en los mercados de fruta fresca en otros países. Sin embargo, el sustento para producir cítricos con calidad se encuentra representado por la inversión que realizan estas mismas empresas en las fases de producción primaria y valor agregado. Por último, otro factor interno de competitividad que presentan las organizaciones antes señaladas, es la obtención de una marca comercial que les ha facultado para contar con sus propios productos diferenciados con respecto a la competencia.

\section{Factores externos de competitividad}

Generalmente, las condiciones del entorno externo afectan a todas las empresas que participan en un determinado sector de la producción, no obstante la clave del éxito organizacional se en-

TABLA 5

\section{MATRIZ DE CONCENTRACIÓN PARA IDENTIFICAR LOS FACTORES INTERNOS DE COMPETITIVIDAD}

\begin{tabular}{|c|c|c|c|c|c|c|}
\hline No. & Factores Internos de Competitividad & Valencia & Eureka & Alkantara & Delta & Total \\
\hline 1 & Certificaciones internacionales & $x$ & $x$ & $x$ & & 3 \\
\hline 2 & Promoción internacional & $x$ & & $x$ & & 2 \\
\hline 3 & Inversión en producción y valor agregado & $X$ & $x$ & $x$ & & 3 \\
\hline 4 & Marca comercial & $X$ & $X$ & $X$ & & 3 \\
\hline 5 & Alianzas estratégicas & $x$ & & & & 1 \\
\hline 6 & Página electrónica & & $x$ & $x$ & & 2 \\
\hline 7 & Manuales de procedimientos & & $x$ & & & 1 \\
\hline 8 & Prácticas de exportación diversificada & & & $x$ & & 1 \\
\hline 9 & Identificación de la satisfacción del cliente & & & $x$ & & 1 \\
\hline 10 & Alianzas comerciales con el extranjero & & & $x$ & & 1 \\
\hline 11 & Laboratorios especializados & & & & $X$ & 1 \\
\hline 12 & Industrialización de cítricos. & & & & $x$ & 1 \\
\hline 13 & Posicionamiento en la industria de cítricos & & & & $X$ & 1 \\
\hline 14 & Planes de expansión a otros estados & & & & $x$ & 1 \\
\hline 15 & Innovaciones tecnológicas & & & & $x$ & 1 \\
\hline
\end{tabular}

Fuente: Elaboración a partir de las entrevistas realizadas (David, 2008). 
cuentra en la forma en que responda cada una a través del diseño e implementación de estrategias (Porter, 1982). En la tabla 6, se concentran los principales factores externos de competitividad de cada empresa estudiada con la correspondiente puntuación ponderada alcanzada.

\section{Sistema Integral de Asociacionismo Empresarial a partir de la identificación de los factores determinantes de competitividad}

Una vez identificada la dinámica originada entre los recursos, capacidades y actividades, en cada una de las empresas estudiadas, además de los factores internos y externos explicativos del éxito competitivo (lo cual permitió el diseño del análisis estructural del sector citrícola), se realizó la propuesta de un Sistema Integral de Asociacionismo Empresarial que contribuya al fortalecimiento del sector citrícola en la región de frente a la competencia interna y externa en un entorno globalizado.

Los objetivos esenciales se delimitan a la creación de conocimiento, el incremento de los rendimientos y la innovación y desarrollo de tecnología, productos, servicios y procesos (Sölvell, 2008). El establecimiento de un sistema sustentado en la asociatividad con objetivos y metas definidas que permitan agregar valor a las organizaciones e indirectamente a participantes de la cadena productiva, se considera determinante para el desarrollo de la competitividad. En este sentido, se plantean los siguientes objetivos estratégicos:

1. Mejorar el nivel de organización

2. Fortalecer las fases de producción primaria, valor agregado e industrialización

3. Consolidar la comercialización e imagen de los productos citrícolas en el entorno nacional e internacional

4. Desarrollo de capital humano

Para alcanzar la competitividad a nivel empresarial mediante el incremento de la productividad y expansión del mercado es necesario que se formen alianzas y redes de cooperación, de tal manera que se compita mediante un esquema de asociatividad (Prokopenko, 1998; Alburquerque, 2006).

Al respecto, se propone la participación articulada no sólo de las unidades estudiadas como referentes de éxito del tejido empresarial, sino también se sugiere la integración de las empresas que se desarrollan como parte del sector social y pequeña propiedad. Además, involucrar al sector gubernamental, universidades y centros de investigación, medios de comunicación y la red de proveedores. En el contexto de tal interacción, a continuación se propone un conjunto de iniciativas con el fin de brindar un sentido de dirección en el conglomerado (Tabla 7).

TABLA 6

MATRIZ DE CONCENTRACIÓN PARA IDENTIFICAR LOS FACTORES EXTERNOS DE COMPETITIVIDAD

\begin{tabular}{|c|l|c|c|c|c|c|}
\hline No. & \multicolumn{1}{|c|}{ Factores Externos de Competitividad } & Valencia & Eureka & Alkantara & Delta & Total \\
\hline 1 & Introducción de nuevas variedades & 0,06 & 0,12 & 0,24 & 0,06 & 0,48 \\
\hline 2 & Mano de obra calificada & 0,32 & 0,32 & 0,32 & 0,32 & 1,28 \\
\hline 3 & Acceso a nuevos mercados & 0,24 & 0,24 & 0,32 & 0,24 & 1,04 \\
\hline 4 & Condiciones climatológicas & 0,30 & 0,30 & 0,30 & 0,10 & 1,00 \\
\hline 5 & Productos procesados (jugo, mermeladas, aceite, cascarilla, pulpa) & 0,20 & 0,10 & 0,10 & 0,40 & 0,80 \\
\hline 6 & Aprovechamiento de acuerdos comerciales con otros países & 0,12 & 0,12 & 0,16 & 0,12 & 0,52 \\
\hline 7 & Superficie para producir grandes volúmenes & 0,30 & 0,30 & 0,40 & 0,10 & 1,10 \\
\hline 8 & Desgravación de los aranceles del jugo concentrado en el TLCAN & 0,08 & 0,04 & 0,04 & 0,16 & 0,32 \\
\hline
\end{tabular}

Fuente: Elaboración a partir de las entrevistas realizadas (David, 2008). 


\section{TABLA 7 \\ LÍNEAS DE ACCIÓN PARA LOS INTEGRANTES DEL SISTEMA INTEGRAL DE ASOCIACIONISMO EMPRESARIAL: SECTOR CITRÍCOLA - ZONA CENTRO DEL ESTADO DE TAMAULIPAS}

\begin{tabular}{|c|c|c|c|c|}
\hline \multirow{2}{*}{ ACCIÓN } & \multicolumn{4}{|c|}{ PARTICIPANTE } \\
\hline & Gobierno & Sector Productivo & Universidad & Red de Proveedores \\
\hline \multicolumn{5}{|l|}{ MEJORAR LOS NIVELES DE ORGANIZACIÓN } \\
\hline Programas sociales armonizados con el sector productivo & $\checkmark$ & $\checkmark$ & & \\
\hline Mayor coordinación intersectorial Gobierno - Gobierno & $\checkmark$ & & & \\
\hline Políticas para la integración de clusters & $\checkmark$ & & $\checkmark$ & \\
\hline Programa Estatal de Fomento y Desarrollo Citrícola & $\checkmark$ & & & \\
\hline Censo agrícola por región, variedad y tipo de empresa & $\checkmark$ & $\checkmark$ & $\checkmark$ & \\
\hline Diseño de mapa citrícola georeferenciado & & & $\checkmark$ & \\
\hline \multicolumn{5}{|c|}{ FORTALECER LAS FASES DE PRODUCCIÓN PRIMARIA, VALOR AGREGADO E INDUSTRIALIZACIÓN } \\
\hline Campañas de control sanitario en plantaciones & $\checkmark$ & $\checkmark$ & $\checkmark$ & \\
\hline Financiamiento a los eslabones & $\checkmark$ & $\checkmark$ & $\checkmark$ & $\checkmark$ \\
\hline Estímulos a la productividad y calidad & $\checkmark$ & & & \\
\hline Marco normativo de protección al productor & $\checkmark$ & & & \\
\hline Viveros con variedades libres de virus & $\checkmark$ & $\checkmark$ & $\checkmark$ & \\
\hline Infraestructura de seguridad social y educación & $\checkmark$ & & & \\
\hline Identificación de fuentes de financiamiento & & & $\checkmark$ & \\
\hline Desarrollo de tecnología & & & $\checkmark$ & $\checkmark$ \\
\hline Proyectos de desarrollo sectorial & & & $\checkmark$ & \\
\hline Incubadora de negocios agroindustriales & & & $\checkmark$ & \\
\hline Investigaciones en postcosecha & & & $\checkmark$ & \\
\hline Laboratorios especializados en biotecnología & $\checkmark$ & & $\checkmark$ & $\checkmark$ \\
\hline Banco de germoplasma & $\checkmark$ & & $\checkmark$ & $V$ \\
\hline \multicolumn{5}{|c|}{ CONSOLIDAR LA COMERCIALIZACIÓN E IMAGEN DE LOS PRODUCTOS CITRÍCOLAS EN EL ENTORNO NACIONAL E INTERNACIONAL } \\
\hline Programas para el consumo interno & $\checkmark$ & & & \\
\hline Programas sobre valor nutricional en consumo de cítricos & $\checkmark$ & & & \\
\hline Infraestructura física y virtual & $\checkmark$ & & & $\checkmark$ \\
\hline Estudios de mercado y planes de comercialización & $\checkmark$ & $\checkmark$ & $\checkmark$ & \\
\hline Desarrollo de nuevos platillos a base de cítricos & & & $\checkmark$ & $\checkmark$ \\
\hline Impulso de eventos citrícolas & $\checkmark$ & $\checkmark$ & $\checkmark$ & $\checkmark$ \\
\hline
\end{tabular}

continúa... 
continuación tabla 7

\begin{tabular}{|l|l|l|l|l|}
\hline DESARROLLO DE CAPITAL HUMANO & & \\
\hline Programas de asesoría técnica & & & \\
\hline Reorientación de la oferta educativa & & & \\
\hline Programas de capacitación continua. & & & \\
\hline Convenios para prácticas profesionales en empresas & & & \\
\hline Investigación aplicada a aspectos citrícolas & & & \\
\hline
\end{tabular}

Fuente: Elaboración propia.

\section{CONCLUSIONES}

El interés por determinar los factores que contribuyen significativamente al éxito y logro de un mejor posicionamiento competitivo de las empresas citrícola, recae en la importancia que representa dicho sector primario en el desarrollo económico del estado de Tamaulipas, y en particular de la zona centro de la entidad. Además de aportar elementos teóricos y metodológicos hacia la profundización de futuras líneas de investigación sobre el tema planteado.

Una vez identificadas y analizadas las actividades representativas de la cadena de valor en las empresas estudiadas, además de los recursos y capacidades de las mismas, así como los factores internos y externos a los cuales se les atribuye el éxito competitivo de tales organizaciones, se realizó la propuesta del Sistema Integral de Asociacionismo Empresarial.

Por lo anterior, al considerar que la proximidad geográfica y una cultura de trabajo similar generan relaciones más estrechas, mejor información y diversas ventajas derivadas de la productividad y la innovación (Porter, 1999), una vez que se ha planificado el nacimiento del Sistema Integral de Asociacionismo Empresarial: Sector Citrícola - Zona Centro del Estado de Tamaulipas, con la finalidad de que transite hacia la fase de madurez o consolidación del clúster, deberá de entrar en un proceso de competencia internacional en los mercados de productos finales derivados de los cítricos.
Ante este panorama, surgirá la atracción de nuevas empresas, la movilidad de capital humano, la creación de una diversidad de recursos financieros y de servicios especializados, el diseño e implementación de estrategias competitivas, la consolidación de infraestructura avanzada y la generación de conocimiento (investigación y desarrollo). Asimismo, se originarán una multiplicidad de enlaces interinstitucionales, al igual que la transformación de ciertas políticas y programas de carácter público.

\section{Referencias}

Acuña, M.; Villalobos, D. y Ruiz, K. (2000). El cluster eco turístico de Monteverde/Costa Rica. Universidad Nacional. Centro Internacional de Política Económica para el Desarrollo Sostenible.

Alburquerque, F. (2006). Cluster, territorio y desarrollo empresarial: diferentes modelos de organización productiva. Cuarto Taller de la Red de Proyectos de Integración Productiva. Fondo Multilateral de Inversiones. Banco Interamericano de Desarrollo.

Alvarez, M. (2011). La localización: estrategias diferenciadas en la industria textil. México: Pearson.

Aragón, A. y Rubio, A. (2005). Factores explicativos del éxito competitivo: el caso de las PyMEs del estado de Veracruz. Contaduría y Administración, 216, 35-69.

Bada, L. y Rivas, L. (2002). Competitividad de los productores de naranja de Álamo, Veracruz. Investigación Administrativa. Escuela Superior de Comercio y Administración Unidad Santo Tomás, 92.

Bair, J. y Gereffi, G. (2001). Local Clusters in Global Chains: The Causes and Consequences of Export Dynamism in Torreon's Blue Jeans Industry. World Development, 29, 1885-1903. 
Bonache, J. (1999). El estudio de casos como estrategia de construcción teórica: características, críticas y defensas. Cuadernos de Economía y Dirección de la Empresa, 3, 123-140.

Buitelaar, R. (2001). ¿Cómo crear competitividad colectiva? La Estrategia Económica del Tolima, Tolima. Centro de Productividad del Tolima/Fondo Colombiano de Investigaciones Científicas y Proyectos Especiales (Colciencias).

Caro, M. y Leyva, C. (2007). El cluster de la industria del software en Mérida, Yucatán. Revista de Contaduría y Administración, 224, 137-157.

Chami, J. (2001). Estrategia de desarrollo de clusters basados en recursos naturales: el caso de la bauxita en el norte de Brasil. Red de Reestructuración y Competitividad. División de Desarrollo Productivo y Empresarial. CEPAL, 105, 5-72.

Chavarría, H.; Sepúlveda, S. y Rojas, P. (2002). Competitividad de cadenas agroalimentarias: elementos conceptuales. Colección de Documentos IICA. Serie de Competitividad, 1.

David, F. 2008. Conceptos de administración estratégica. México: Pearson Education.

De la Cruz, I. (2007). Capacidades y estrategia competitiva: propuesta de un modelo para su desarrollo dentro de un sector. Revista de Administración, Finanzas y Economía, 1, 125-133.

De la Cruz, I. (2008). Capacidades gerenciales y funcionales y ventaja competitiva desde la perspectiva de la visión basada en recurso en las pequeñas y medianas empresas del sector comercial de distribución de equipo multifuncional en México. Tesis Doctoral, Instituto Tecnológico y de Estudios Superiores de Monterrey Campus Ciudad de México.

Demuner, M.; Aguilera, M. y Hernández, A. (2010). El proceso de competitividad empresarial en PyMES. Sistemas de Innovación para la Competitividad 2010 (SINNCO), Observatorio de Ciencia, Tecnología e Innovación, Gobierno del Estado de Guanajuato, ISBN 978-607-95030-7-9, 125-133.

Díaz, C. (2010). Naranja dulce, limón partido. Revista Claridades Agropecuarias, 197, 32-39.

Díaz, H. y Feria, M. (2008). El cluster mueblero en Aguascalientes. Un análisis de innovación y competitividad empresarial. VI Congresos Internacional de Análisis Organizacional: "Perspectivas multidisciplinarias en análisis organizacional: complejidad, ambigüedad y subjetividad".

Díaz, R. y Hartwich, F. (2005). Cadenas de valor: un paso innovador para la agricultura Centroamericana. Alternativas para el Desarrollo, 96, 1-14.
Eisenhardt, K. (1989). Building Theories from Case Study Research. Academy of Management. The Academy of Management Review, 14, 4, 532-550.

Estrada, R.; García, D. y Sánchez, V. (2009). Factores determinantes del éxito competitivo en la Pyme: Estudio Empírico en México. Revista Venezolana de Gerencia, $14,46,169-182$.

Federación Argentina del Citrus (2011). La Actividad Citrícola Argentina. Recuperado de: www.federcitrus.org.

Gobierno del Estado de Tamaulipas. (2011). Plan Estatal de Desarrollo 2011- 2016.

Hernández, R.; Fernández C. y Baptista, P. (2003). Metodología de la investigación, 3era. ed., México: McGraw-Hill.

Instituto Nacional de Estadística y Geografía e Informática. (2007). Censo Alimentario.

Instituto Nacional de Estadística y Geografía e Informática. (2009). Censo Agrícola, Ganadero y Forestal.

Jiménez, M. (2006). Modelo de competitividad empresarial. UMBral Científico, 9, 115-125.

Martínez, S.; Charterina, J. y Araujo, A. (2010). Un modelo causal de competitividad empresarial planteado desde la VBR: capacidades directivas, de innovación, marketing y calidad. Investigaciones Europeas de Dirección y Economía de la Empresa, 16, 2, 165-188.

Meyer-Stamer, J. y Harmes-Liedtke, U. (2005). Como promover clusters. Banco Interamericano de Desarrollo.

Montegut, Y. (2006). Análisis de los factores explicativos del éxito competitivo en las almazaras cooperativas catalanas. Tesis Doctoral, Universitat de Lleida, Facultad de Dret i Economía.

Montero, C. (2004). Formación y desarrollo de un cluster globalizado: el caso de la industria del salmón en Chile. Red de Reestructuración y Competitividad. División de Desarrollo Productivo y Empresarial. CEPAL, 145, 1-75.

Namakforoosh, M. (2006). Metodología de la investigación. México: Limusa.

Padilla-Bernal, L.; Reyes-Rivas, E. y Pérez-Veyna, O. (2010). La eficiencia colectiva en el cluster del tomate bajo agricultura protegida de Zacatecas. Ponencia presentada en el XIV Congreso Internacional de la Academia de Ciencias Administrativas, A.C. (Monterrey, N.L., abril de 2010).

Penrose, E. (1959). The Theory of the Growth of the Firm. 4a. ed., New York, Oxford Press. 
Piña. H. (2004). El Conglomerado Zábila (Aloe Vera) en el Estado Falcón, Venezuela. Cuadernos de Desarrollo Rural, 053, 37-57.

Porter, M. (1982). Estrategia Competitiva. Técnicas para el análisis de los sectores industriales y de la competencia. México: CECSA.

Porter, M. (1987). Ventaja Competitiva. Creación y sostenimiento de un desempeño superior. México: CECSA.

Porter, M. (1999). Los clusters y la competencia. Harvard Business Review, 2, 30-45.

Prokopenko, J. (1998). Globalización, competitividad y estrategias de productividad. Boletín Cinterfor, 143, 33-70.

Ramos, J. (1998). Una estrategia de desarrollo a partir de los complejos productivos (clusters) en torno a los recursos naturales. Comisión Económica para América Latina y el Caribe (CEPAL).

Rodríguez, G.; Gil, J. y García, E. (1999). Metodología de la investigación cualitativa. $2^{\text {a }}$ ed., España: Aljibe.

Rodríguez, Á.; Bañuelos, K.; Rubio, B. y Chávez, J. (2010). Factores internos que afectan a la competitividad en las empresas de la zona sur de Tamaulipas. Revista de la Ingeniería Industrial, 4.

Romo, D. y Abdel, G. (2005). Sobre el concepto de competitividad. Comercio exterior, 55, 200-214.

Rubio, A. y Aragón, A. (2008). Recursos estratégicos en las pymes. Revista Europea de Dirección y Economía de la Empresa, 17, 1, 103-126.

Rueda, I. (1997). Las empresas integradoras en México. 1a ed., México: Siglo xxi.

Saavedra, M. (2010). Hacia una propuesta metodológica para la determinación de la competitividad en la PyME. Ponencia presentada en la XII Asamblea General de la Asociación Latinoamericana de Facultades y Escuelas de Contaduría y Administración.

Sanfiel, M.; Oreja, J.; García, A. y Álvarez, P. (2005). De los vínculos interorganizativos con escaso grado de interrelación o interdependencia a las redes de empresas. Ponencia presentada en el XV Congreso Anual de ACEDE (La Laguna, ISBN: 84-689-2732-5).

Secretaría de Agricultura, Ganadería, Desarrollo Rural, Pesca y Alimentación (2004). Programa Alianza para el Campo. Diagnóstico y Plan de Acción del Sistema - Producto Cítricos Tamaulipas.
Secretaría de Agricultura, Ganadería, Desarrollo Rural, Pesca y Alimentación (2009).

Secretaría de Agricultura, Ganadería, Desarrollo Rural, Pesca y Alimentación (2011).

Server, R. y Mateos, A. (2003). Los costes de calidad en las empresas citrícolas y su identificación en el marco del sistema de costes basado en las actividades. Economía Agraria y Recursos Naturales, 3, 105-121.

Silverman, D. (1993). Begining Research. Interpreting Qualitative Data. Methods for Analysing Talk. Text and Interaction, Londres: Sage Publications.

Sölvell, Ö. (2008). Clusters. Equilibrando Fuerzas Evolutivas y Constructivas. $1^{\text {a }}$ ed., Estocolmo: Ivory Tower Publishers.

Taboada, E. (2004). ¿Qué hay detrás de la Decisión de Cooperar Tecnológicamente? Propuesta Teórica Integradora para Explicar la Cooperación Tecnológica Inter-Firma. Tesis Doctoral, Universidad Autónoma Metropolitana, 2004.

Unger, K. (2003). Los clusters industriales en México: especializaciones regionales y la política industrial. Comisión Económica para América Latina y el Caribe (CEPAL).

Urgal, B. (2005). Algunas reflexiones de síntesis sobre la evaluación del carácter estratégico de los recursos y las capacidades de la empresa. Cuadernos de CC.EE. y EE., 48, 35-59.

Velázquez, M. y Maldonado, S. (2010). Detección de las causas determinantes de la formación del clúster de la agroindustria del jitomate: propuesta de un instrumento de medición. Ponencia presentada en el XIV Congreso Internacional de la Academia de Ciencias Administrativas, A.C. (Monterrey, N.L., abril de 2010).

Vera, J. y Ganga, F. (2007). Los clusters industriales: precisión conceptual y desarrollo teórico. Revista de Administración. Bogotá, Colombia.

Villafán, K.; Guitrón, M.; Pedraza, O. y Bonales, J. (2007). Cluster aguacatero en el estado de Michoacán, México. Actas VI Congreso Mundial del Aguacate. Viña del Mar, Chile..

Yin, R. (1991). Case Study Research. USA: SAGE.

Recibido: 15 de enero de 2013 Aceptado: 12 de abril de 2013 